\section{Applicability of Freeze-Fracture and Cryo-TEM to Complex Liquids}

Janet L. Burns and Richard J. Spontak, The Procter \& Gamble Company

Traditional methods of sample preparation and analysis in conventional transmission electron microscopy (TEM) are not readily applicable to multicomponent complex liquids which may contain a wealth of microstructural information. Two techniques which facilitate the study of structure in such liquids are freezefracture (FF) TEM and cryo-TEM.

FFITEM has been exceptionally valuable in probing the ultrastructure of biomembranes. The principles behind FF/TEM can be easily extended to study the morphological details of various structures in complex liquids. Vitrified specimens are fractured at low temperature and under high vacuum to produce surfaces which are replicated and examined. We have had tremendous success in characterizing multilamellar vesicles and sheets with this technique.

When the microstructural elements are sufficiently small, cryo-TEM is used to image the elements in situ. The liquid forms a thin film on a TEM grid and is rapidly cooled and transferred to the microscope under cryogenic conditions. Small-scale structures such as micelles, vesicles, and lipid sheets, have all been successfully visualized with cryo-TEM.

Information regarding colloidal microstructure is necessary in understanding the meological and stability properties of various complex liquids. Cryo-TEM and FF/TEM are essential analytical tools for developing structure-property relationships.

\section{CONTEST RESULTS}

In the last issue of this newsletter, sort of as a space-filler, we announced a contest. The first question of this contest was what is the most common last name in our mailing list of over 9,500 individuals with an interest in microscopy in the U.S.? The second question was how many are there with that name?

The prize of a $\$ 50$ U.S. Savings Bond would be awarded to the individual who correctly answered the first question and came the closest on the second. The winner is Ms. Dawn Hommes (Abbott Labs, Abbot, IL) who picked the number of "Smiths" at 55 and her $\$ 50$ U.S. Savings Bond is on its way. The last names, and number, of the highest ten last names on our list are as follows:

$\begin{array}{llll}\text { Smith } & 57 & \text { Anderson } & 29 \\ \text { Johnson } & 47 & \text { Lee } & 28 \\ \text { Miller } & 41 & \text { Jones } & 27 \\ \text { Brown } & 38 & \text { Williams } & 27\end{array}$

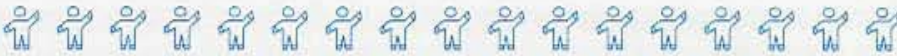

One of the first indications of a really bad day is when one must use their Mastercard to pay off their Visa Card Galance.

\section{(HARLES EVANS: ASSOClATES}

SPECIALISTS IN MATERIALS CHARACTERIZATION

\title{
Semiconductor Precision Cross-Sections
}

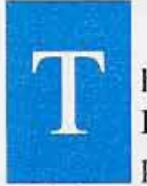

he Charles Evans \& Associates' EM Laboratory in Redwood City, California provides ultra high quality SEM and

TEM cross-sections of specific integrated circuit devices with a lateral accuracy of less than $0.5 \mu \mathrm{m}$. The laboratory is equipped with a JEOL JSM 6300F FE-SEM ( $15 \AA$ resolution), a JSM 890 Immersion Lens FE-SEM ( $7 \AA$ resolution), and a JEM-2010,200 kV TEM (1.4 Å lattice image resolution). For further information on precision cross-sections or EM services, please contact Doug Hamilton, Manager of Electron Microscopy.

\section{(HARLES EVANS E ASSOCIATES}

SPECIALISTS IN MATERIALS CHARACTERIZATION

301 Chesapeake Drive

Redwood City, CA 94063

(415) 369-4567 • FAX (415) 369-7921
SEM micrograph shows $0.05 \mu \mathrm{m}$ diameter voids in the center of submicron tungsten via plugs.

TEM micrograph shows tungsten-silicide on poly two and ONO interpoly dielectric from a flash EPROM memory cell.

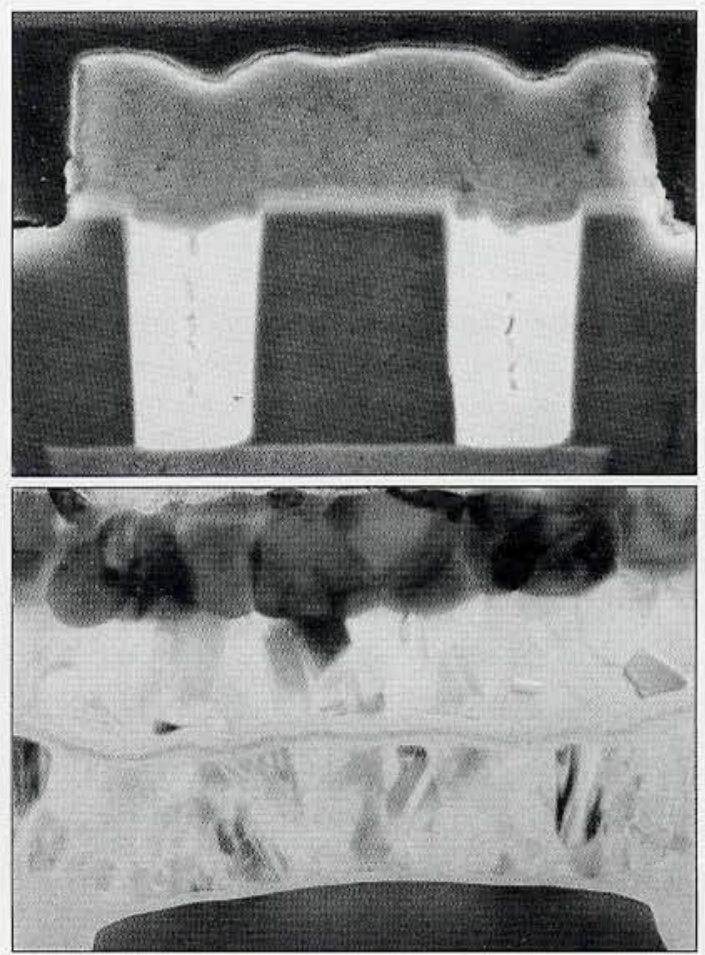

